\title{
The Unique Charm of the Context to the Architectural Environment
}

\author{
Shengxiao $\mathrm{Li}^{1, \mathrm{a}}$, Jun $\mathrm{Ma}^{1, \mathrm{~b}}$ and Guanghui $\mathrm{Lv}^{2, \mathrm{c}}$ \\ ${ }^{1}$ Architectural Design and Research Institute, Shenyang Jianzhu University, Shenyang, 110168, \\ China P.R. \\ ${ }^{2}$ College of Civil Engineering, Shenyang Jianzhu University, Shenyang, 110168, China P.R. \\ alishengxiao@163.com ,byasyn@163.com , c1052555181@qq.com
}

\section{Keywords: Architectural environment, context, characteristics}

Abstract: The theoretical summary and example analysis are applied in this article, that study how to make the building environment fully display the history and bring charm characteristics by culture. To carry forward the national essence culture, enable the building environment and culture to the exterior design, and create rich culture architectural environment.

\section{Introduction}

Humans have intuitive itself from the historical and cultural nature, especially the Chinese people have a statue of $\mathrm{ZuChongZu}$ national habits, pay attention to context inheritance and continuation. Archaism cloud: "The appropriate view this disaster, no ancient not today". ZuChongZu, aimed at strengthening national unity, arouse the sense of national pride; Context, aims to carry forward the essence of national culture, towards the new peak. Context refers to the dialogue between various elements of inner link, more precise, refers to the partial and whole dialogue between inner link.

In the design of architectural environment, also should reflect on history, context, and explore the spiritual value. And care for the first half of this century modernism period meet function compared with the formal language, stress the significance of metaphor and design has become increasingly common in today's architectural design, become one of the characteristics of the western contemporary square design tendency. Many designers in order to reflect the history of natural ideal or base and the environment, through cultural form in the design of the space metaphor to create meaningful content and form, and give meaning to building environment makes it easy to understand.

Commonly used design methods are divided into the environmental context contextual ism methods and techniques of the historical context, and the postmodern. Environment context, the architectural space as a citizen in whole way of life and social culture pattern of "symbol", regional characteristic, set the simile; Historical context, pay attention to extracted from traditional architectural symbols, convey history information, with modern architectural dimension, space with traditional modeling elements, detail segment compatibility, grasp the context from the Angle of time, set the metaphor; Postmodern technique, will represent the each period of Chinese culture in abstract representation of all sorts of things, make people produce lenovo, metaphor is a kind of symbolic and design.

\section{The Environmental Context}

In China for thousands of years history of excellent landscape to the people left a deep impression, and extensive landscape also buried deep under the traditional national culture psychology and

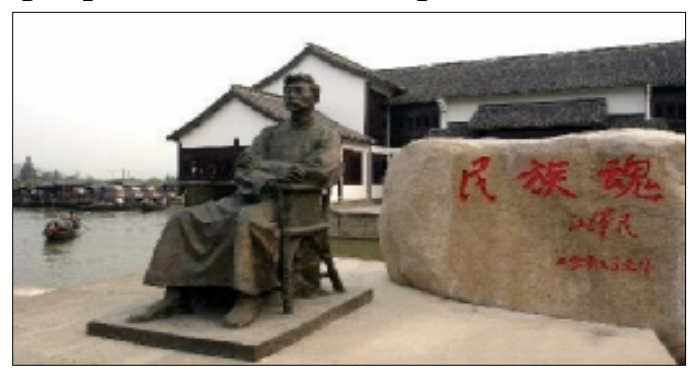

Figure 1 former residence of Shaoxing Lu Xun 
aesthetic characteristics. So we convergence and collision of eastern and western cultures in today's era, must according to the reality of the Chinese culture, especially the Chinese actual living habits and aesthetic habit of building environment requirements, on the active introduction of international advanced design ideas and the latest designs at the same time, also want to building environment of technology and art in China with Chinese cultural characteristics and conforms to our country national psychological aesthetic exploration of building environment design.

Feng Shui Theory for the Chinese view of nature and aesthetic view of the formation and the living environment choice, it not only create a deep meaningful national culture, but also will remain its exuberant vitality. Advocating nature, return to nature, the pursuit of harmony between man and nature is the common ideal of mankind. Human understanding of nature from the initial fear, worship, to the development of the natural intimacy, praise is a human aesthetic awareness of the awakening. Chinese people have always been to the water to the deep, and try to use a variety of methods of water, water, water, environment, the harmony of the three. Chinese people attach importance to water, it is through the water to express the natural, environmental, life attitude.

Shaoxing lu xun's former residence environment (see figure 1), the biggest characteristic is a feature of shaoxing water obviously. Before construction square with besides, people can arrive from the south side of the road, also can take a boat through the bridge to reach the moon square before construction, can also arrive masonry bridge crossed from the west, sinking square near masonry bridge, can make the people close to the surface. Stone bridge, WuPengChuan, connected to the surface of the steps are reflects the characteris-

Tics of water,permeate a local context characteristics, with the surrounding environment coordination. Buildings around the horsehead walls, white wall tiles is concise and lively, well combine modern style and characteristics of shaoxing folk house, make him appear in traditional culture, building, set each other off becomes an interest, water, bridge, water character, memorable.

Chongqing is a unique geographical and cultural style and historical and cultural traditions of the two rivers to encircle the riverside mountain city, Yishanbangshui the building, the city with the mountain,structured,three-dimensional sense of strong(see Figure 2). Compared with flat open plain city, mountain city is affected by terrain, the size and the shape of the outer space environment is limited. But in turn, by the topography, creating a different elevation plane group and space formation of Taiwan Wai, the space of interest, to meet the different needs of people outside the building space activities; mountain city in the mountains on the potential of Diaojiaolou houses, cliffs overhanging the Taoist temple buddhist

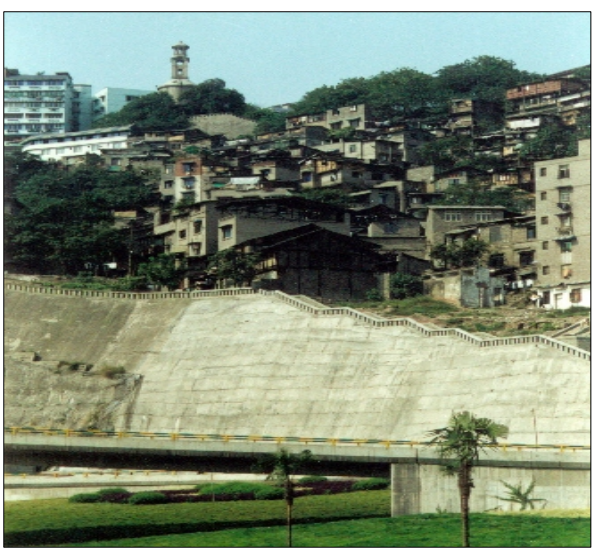
temple, built Taiwan Cuoceng, UPS and downs, overhead attached to rocks are all according to the landform, dependent on the natural results.

\section{The Historic Context}

The historical context, emphasized the importance of time experience. In order to strengthen people experience and comprehension of time, with the historical context, spatial sequence, the natural environment for reference frame. Inheriting the historical context, bring people into the distant past

Figure 2 Chongqing Mountain Fortification

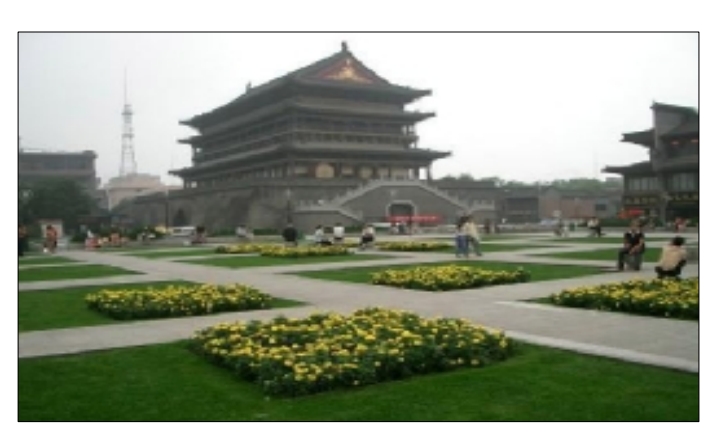

Figure 3 Xi'an Bell Tower and Drum Tower 
memorial; Extend the space sequence, the time history of start roaming; Beautify the environment, let people experience the fruitful achievements of gorgeous. The historical context of the

city is a logical thing, especially in urban and rural areas of our country, influence the historical environment everywhere. Need to use the cultural perspective to find, the culture of the mind to think, cultural progress to promote, this is the role of the construction culture. Traditional city is the symbol of human civilization, and it is the main carrier of the development of civilization. Among all the functions of the city, the collective memory is important, and it is the soul of the city. A stone, a water well for the native people naturally cordial, familiar, recognition; for foreign guests and children also played a specific symbol, cognition and the role of the conviction. Of course, the positive attitude to the traditional remains is the combination of protection and utilization, the purpose is still for today's service.

$\mathrm{Xi}$ 'an bell tower (see figure 3) the design of the building external environment, highlights the image of the two ancient building first, keep their visual effect. On the design elements adopted with metaphor a number of design of Chinese traditional culture, make contacts in the building square people can enjoy the flavor of traditional culture. Has become a very has the sense of personality, increase the drum tower as attractive and tolerance of the "city living room". At the same time, the drum tower square as the center, south to south street, the academy gate, the forest of steles, strong on the north gate, temple, mosque, the formation of a traditional means of pedestrian system, the drum tower square to become the hub of the ancient capital culture in xian. To create a full, rich historical and cultural connotation, and for the future urban architecture environment.

Shanghai jing an temple square (see figure 4) the whole pattern of use the technique of match well of Chinese and western. Shanghai is a city of Shanghai style culture, in Shanghai, the evolution history of the western culture occupies an important position. Nanjing road of context is 20 to $30 \mathrm{~s}$ of this century to build the basis of the western classical architecture, but also the inclusion of Chinese and western architecture of the conflict. And jing 'an temple square is located in the focus of the conflict, the representative of the western culture of nanjing road and the Chinese civilization on behalf of the jing an temple in the north of the square. So square area to inherit the traditional architectural form, don't shy away from conflict, and to consider The Times. To this end, will become a distinctly western subsided square design style, like the Roman arena of semicircle corridor, and form set off to the north of jing an temple. Around the square green space with Chinese culture is converted to western-style gardens, the west of tree species, sculpture, with the Chinese style pavilion the harmonious unification, visitors can deeply feel the Shanghai's unique cultural characteristics.

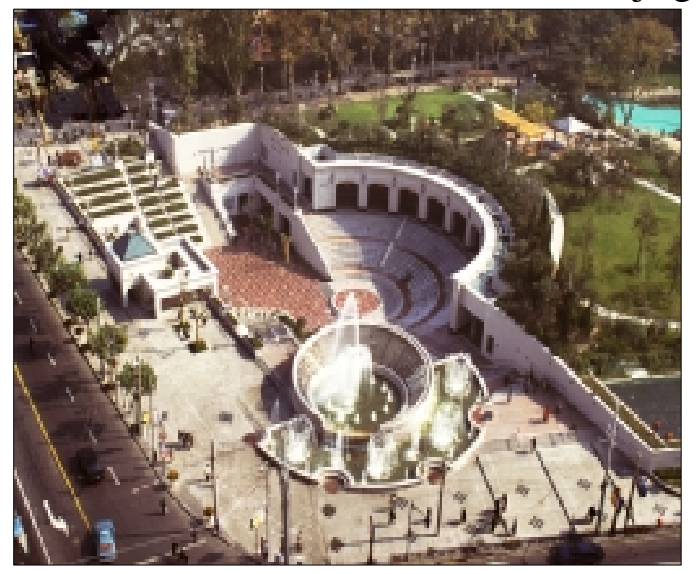

Figure 4 Shanghai Jingan Temple square

\section{The Postmodern Technique}

When the madman Nietzsche declared "god is dead", rational world of western society has been an unprecedented question and subversion, all kinds of irrational thoughts in succession in the western world. In the architecture environment design in the performance of the postmodernism is the most dazzling. Postmodern introduced a concept of symbol and metaphor, in a game of vocabulary, breaks the traditional hero's theme of building environment design, and replace it with a "narrative", in the urban space to create the emotional world of a man. 
"Symbol" as an expression from the literature. A symbol, is to use specific things to express a kind of special meaning and image, rather than illustrate the things themselves, or borrow this to him. Such as the rose is the symbol of love, the peony is a symbol of wealth, the dove is the symbol of peace, the red palace, the Forbidden City yellow glazed tile has expressed first a symbol of imperial power. Symbol belongs to the symbol system, concern expressed by the symbolic significance, is the human cultural exchanges and communication between media and means.

Metaphor "is a common concept in Linguistics and hermeneutics, which is developed with the development of post modernism and semiotics. "Metaphor" is a "metaphor" in the form of a signifier from the right place to the other, and thus to the latter, "said Graves". The essence of metaphor is "spirit likeness", seeks to capture the artistic features of the form of new and old buildings and give the new building, and performance, this kind of performance is not clear, but extract, abstract, sublimation. Reference fragments of history, these out of the context in the form of scattered into several fragments and deformation or change position, change materials, changes in the mix. These fragments freely is arranged on the square design, the form to obtain the new multiple value and meaning. Combined fragments should not copy the original, and to after deformation and in free form deformation, which the resurrection moment in the original language, and endows them with new ideas.

\section{Conclusion}

Chinese art master Guanzhong Wu successfully inherit and carry forward the essence of traditional art Chinese. He said: "the various forms of traditional, the form itself is forever in the development, the nationalization of oil painting is certainly not to the traditional form of dress. I first without considering the problem of form, I only the pursuit of artistic conception, Oriental sentiment, national temperament, and the elders uncles, brothers and sisters shared feeling. People will never forget the mother, people always love read home, 'loved' basic core is nostalgia, is the national habit of appreciation ". China Architectural and environmental design with Chinese characteristics theory of building environment, construction of the unique and excellent architectural environment with Chinese characteristics, showing our fine national wisdom and leisurely the infinite charm, to revive the treasures of the Chinese nation.

\section{References}

[1] Deci Zou. Introduction to urban design: Ideas - methods - practice. Beijing: China Building Industry Press, 2003

[2] Xianjue Liu. Modern architectural theory - the new achievement of the combination of architecture and Humanities Science and technology science. Beijing: China Architecture Industry Press, 2003

[3 Qinnan Zhang. Characteristics of the victory of the architectural theory. Beijing: Mechanical Industry Press, 2005

[4] Guanzhong Wu I negative painting -- The Autobiography of Wu Guanzhong. Beijing: People's Literature Publishing House, 2004 